\title{
A STATE OF THE ART REVIEW OF EFFICIENCY THE FLEXURAL STRENGTHENING OF REINFORCED CONCRETE BEAM BY USING FIBER REINFORCEMENT POLYMER MATERIALS
}

${ }^{*}$ Wissam S. Abdullah ${ }^{1}$
Hassan F. Hassan ${ }^{1}$

1) Civil Engineering Department, College of Engineering, Mustansiriyah University, Baghdad, Iraq

\begin{abstract}
Fiber Reinforced Polymer (FRP) materials are commonly used in civil engineering construction purposes owing their advantages like lightweight, corrosion resistance, high strength, various types available, ease of installation, lower installation costs, shorter construction time and lower maintenance cost [1]. Over the last few decades, flexural Reinforced Concrete (RC) beams reinforcement and maintenance with Near-Surface Mounted (NSM) or Externally Bonded Reinforcement (EBR) Fiber Reinforced Polymer has gained considerable interest and obtained widespread acceptance among civil engineers [2]. This paper reviews previous research on RC beam strengthening by NSM or EBR FRP technique and show the effects of FRP strengthening on flexural strength of RC beam.
\end{abstract}

Keywords: FRP material, Flexural strength, NSM, EBR

\section{Introduction}

Concrete structures may become deficient by time, necessitating reinforcement and maintenance. This requirement can arise of design or construction defects, existing code design revisions, functional changes, structural changes required, poor maintenance, increased traffic volumes, earthquakes, fires and explosions or damage sustained over time. Due to the high cost of replacing deficient structure, strengthening has become a viable option for increasing load and extending the service life. However complete replacement of a defective construction is a choice, strengthening is always the most cost-effective alternative, so as a result, civil engineering structure renewal has received a lot of attention in recent years all over the world. [3]. FRP composite is a modern form of building material made up of fibers and resins. The mechanical properties of FRPs are determined by the mechanical behavior of both the fibers and the resin, as well as their interaction [4]. The manufacturing process, the volumetric ratio of the fibers, the orientation and the shape of the fibers also influence the mechanical properties of the FRP [5]. FRP material is used in the shape of laminate, bar, sheet and spray FRP in concrete structure. The fibers' primary function is to provide high tensile strength and stiffness, while the resin is used to tie the fibers together and keep them save from environmental harm. The most commonly used fibers in structural applications are carbon, glass, and aramid Figure (1) shown some types of FRP materials.

*Corresponding Author: wissam.samir90@gmail.com 


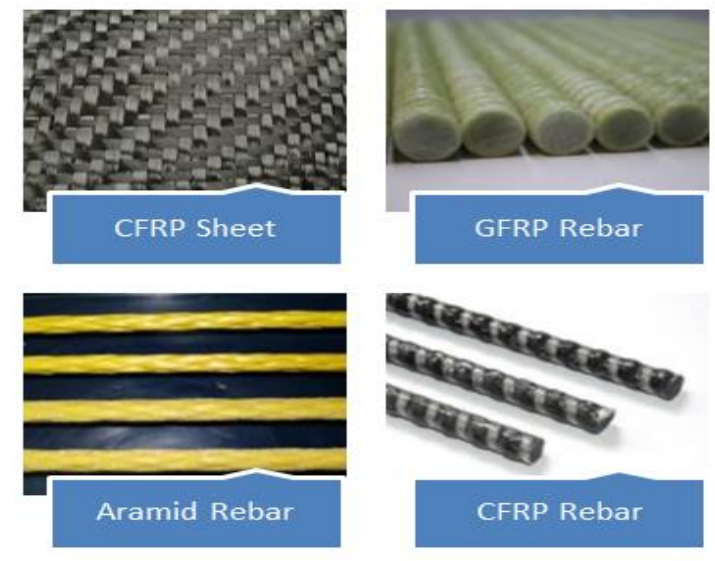

Figure 1.Types of FRP products

FRP materials have many advantages[6] such as Lightweight due to FRP have a density of (1/4) to $(1 / 5)$ that of steel, high tensile strength due to FRP's tensile strength is (4-10) times that of ordinary low carbon steel, corrosion resistance due to FRP composites can normally withstand corrosion in acidic, alkaline, salty, and other environments, compared to other materials, the fiber can be applied quickly and easily due to its light weight, ease of handling and transportation on-site and it is less costly to rehabilitate than other items and has a longer service life. The disadvantages of FRP are high initial cost as well as the fragile nature of FRP bars. Furthermore, FRP cannot extend as far as steel bars without splitting so FRP bars aren't bendable and formable it in the site. Another downside to using FRP is the lack of experience dealing with these materials in terms of design or on-site implementation, as well as the incompleteness of some design criteria and determinants [7]. An inspection of the current structure should be performed to select the beat strengthening strategy first evaluate the concrete's quality, identify the sources of weaknesses, evaluate the structure's present load carrying ability, and assess the viability of employing the selected strengthening process. Assessment of a current building must be done with great caution, the following details should be considered, the dimensions of a concrete structure, as-built drawings with all previous changes, the properties of the present materials, cracks, spalls and steel corrosion are described by their position, scale, and cause, the amount of current reinforced steel and where it is located, An accurate assessment of the applied loads [8].The factors interfering with the choice of a strengthening method [9] are operating time schedule, budget and financial constraints, structure's necessary useful life (The owner's goal should be compatible with the strengthening program), for example, if a building would be demolished within few years, only the bare minimum of strengthening should be done, weather's effect and the environment condition of the area, the impact of strengthening on the loading mechanism for other structural members nearby and architectural requirements.

\section{Failure Modes}

Failure of RC beam strengthened by FRP materials can occur through a variety of mechanisms, depending on the beam and the FRP material. Bonding failed of the FRP, concrete crushing, fracture of the FRP, and shear or flexural failure with steel yielding are the most common modes of failure of RC beam strengthened by FRP materials.

\subsection{Bonding Failure}

The most general type of failure in FRP strengthened systems is bonding failed. Which can be categorized as concrete cover separation, plate end deboning. Bonding failed occurs at the concrete-adhesive interface of an EBR technique because of low binding between the adhesive and the concrete, that could be caused by lack surface preparation [10] as shown in Figure (2).Concrete cover separation occurs because the interface bond strength is much greater than concrete's tensile strength. Similarly, cover separation is the 
most common bonding failed in NSM technique [11] as shown in Figure (3).

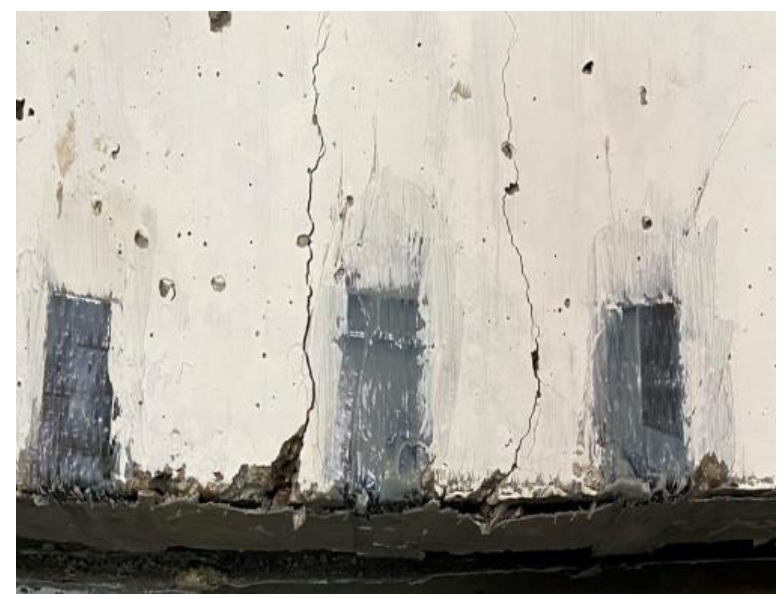

Figure 2. Debonding failure for EBR

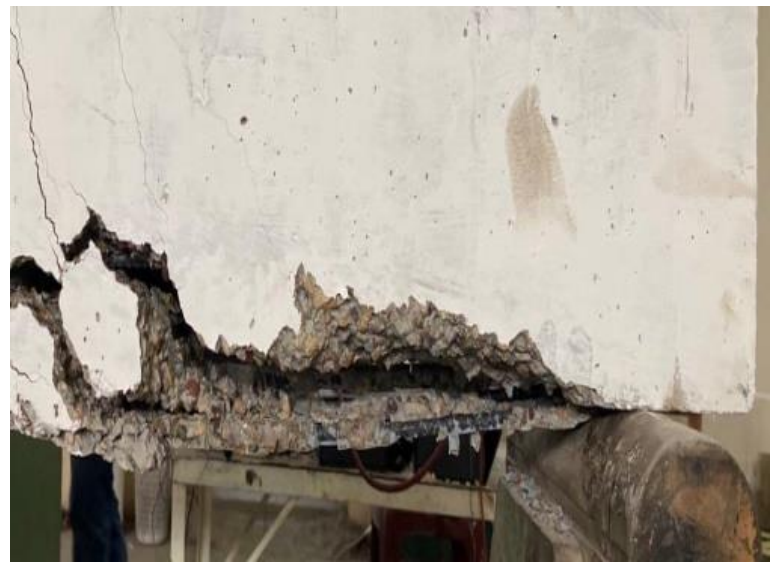

Figure 3. Concrete cover separation for NSM

\subsection{Rupture of FRP Strips}

FRP rupture after localized bonding failed is the most prevalent type of failure of fully wrapped strengthened RC beams. FRP rupture usually happens when the strain in FRP reaches to design rupture before the concrete reaches its maximum strain [2] as shown in Figure (4).

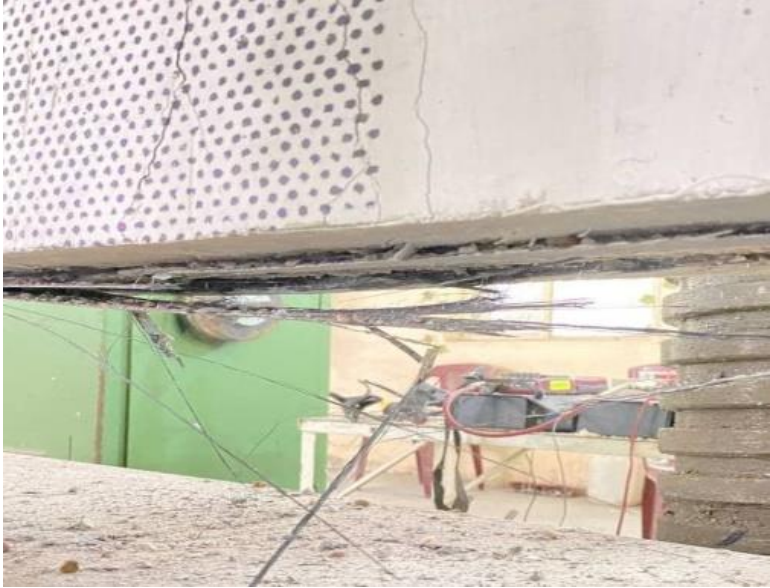

Figure 4. Rupture of FRP strips

\subsection{Splitting of Concrete}

Crushing of concrete in the compression zone occurs when compressive strain in concrete reaches maximum strain [2] as shown in Figure (5). Another form of failure may be distinguished by failure of the materials.

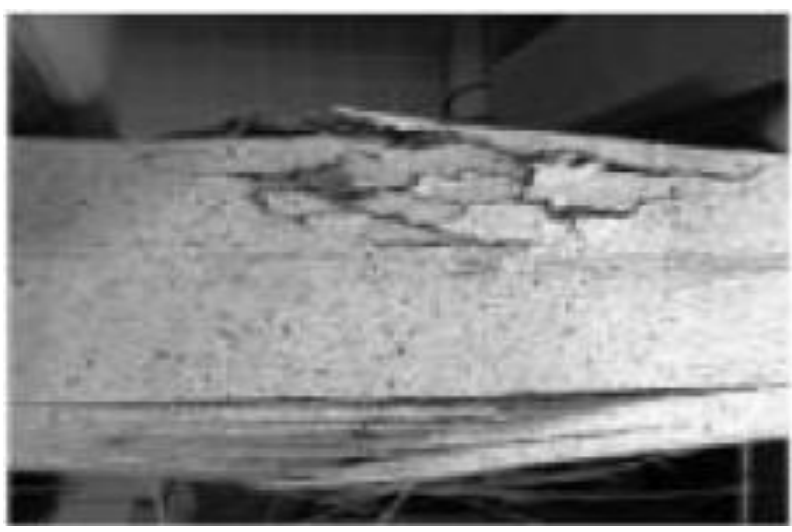

Figure 5. Concrete crushing in compression

\section{Past Experience}

\subsection{Externally Bonded Reinforcement (EBR) For Flexural Strengthening}

FRP material (sheet, laminate, and strip), pre stressed or non-pre stressed, is applied externally to the tension side for flexural strength of a beam by a suitable adhesive as shown in Figure (6). 


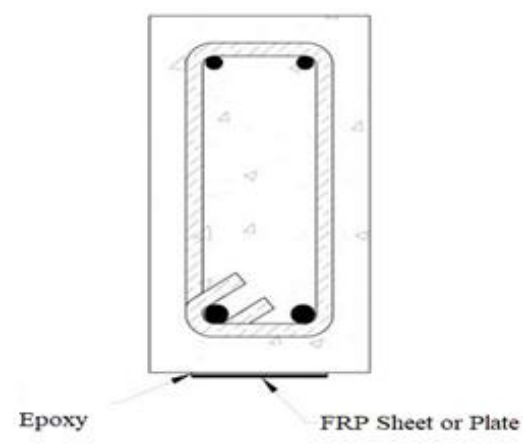

Figure 6. Externally bonded reinforcement for flexural strength

To prevent FRP material peeling and bonding failed, the concrete surface should be prepared and the concrete cover should be in good condition. Popular methods such as grounding and sandblasting will be used to improve the bond strength between the concrete surface and the FRP materials. The most critical features of EBR system in strengthening application is their speed and ease of application. The drawbacks of the EBR system over the NSM system are that the FRP material will be exposed to fire, impact, or collision without any protection and will be more liable to bonding failed from the concrete surface [12].The flexural behavior of RC beams strengthened with EBR-CFRP laminates studied by Mohammed (2007) [13]. The objectives of this research was to determine how the shape, number of CFRP layers, length of CFRP strip and configuration of external anchorage impact on the results. External anchorages, according to the study, are very effective for increasing contact between the CFRP and the concrete, reducing deflection, increasing crack load, and increasing ultimate load up to $111.76 \%$ compared to the reference beam. The ultimate load carrying ability of strengthened beams is improved by increasing the number of laminate layers of CFRP. The carrying capacity of the ultimate load has increased by $14 \%$. The behavior of repaired and strengthened RC beams by CFRP sheet studied by Husain et al.(2009)[14]. The main parameters in this study are allocation, quantity and position of CFRP sheets. The anchorage at the beam's ends was added to avoid CFRP sheet end bonding failed. They found that using CFRP sheet as external reinforcement improved crack pattern, ultimate load, and deflection significantly. The mode of failure of strengthened beams was steel yielding followed by CFRP rupture. They found that using CFRP sheet to reinforce or repair beams could increase the ultimate load capacity by $160 \%$ compared with unstrengthen beam. Although the conduct of repaired and reinforced beams was similar, the maximum load strength of repaired beams was (95\% to $97 \%$ ) of beams that have been strengthened. The increment in peak load of beams which strengthened by EBR-CFRP sheet was proportional to the total area and the amount of configuration of CFRP sheets. The behavior of $\mathrm{RC}$ beams strengthened in flexure with EBRCFRP and GFRP sheets studied by N. Attari et al. (2012) [15] due to high ductility of GFRP and high strength of CFRP. They came to the conclusion that using twin layers of Glass and Carbon sheets to strengthen $\mathrm{RC}$ beams is very effective. The ultimate load capacity of strengthened beam increased by $114 \%$ compared to the reference beam and the $\mathrm{U}$-anchorage also increases the flexural strength. They found that when strengthened beam with GFRP sheet having an ultimate load equal to that of CFRP sheet, this finding is very important in terms of cost efficiency. The influence of the CFRP sheet on deflection studied by Louis et al. (2013) [16].The total depths of beams were $(100,133$, 160 and $200 \mathrm{~mm})$. Except for two beams that have been reinforced with $\left(2 * \rho_{\text {min }}\right)$ and $\left(\rho_{\max }\right)$, all beams have been reinforced with $(\rho$ min).They found that using CFRP sheets for strengthening beam has a significant impact on deflection through raising beam stiffness, mainly after pre 
cracking point, and that using CFRP sheets resulted in a decreases in deflection of (26.7\%) and an increase in maximum load ability by (83\%) when compared to reference beam. The ratio of (Span/depth) played major role in the impact on load-deflection response, as reducing the (Span/Depth) ratio from $(20)$ to $(15,12.5$, and 10) lead to reduces the deflection by $(21 \%, 30.3$ $\%$, and $41.6 \%$ ) respectively, while increasing the ultimate load capacity by $(17 \%, 68 \%$, and 85 $\%)$, respectively. The response to load deflection is marginal influenced by raising the steel reinforcement ratio at a pre-crack point, but this effect has changed at a crack point, the increasing of the steel reinforcement ratio to $(2 \times \rho \min )$ and $(\rho \max )$ as opposed to $(\rho \min )$, decreased the deflection by (13.5 and $29.2 \%$ ), respectively. The flexural behavior of RC beams strengthened with combination between NSM and EBR by using (T-shaped profile) CFRP material as shown in Figure (7). Studied by Kotynia et al. (2015) [17]. The main parameters, compressive strength of concrete classes of (C30/37) or (C50/60) and the ratio of CFRP reinforcement added. (CFRP/T-shaped) profiles had web thicknesses of $4 \mathrm{~mm}$, flange thicknesses of 3.5 $\mathrm{mm}$, and web heights of 15 or $30 \mathrm{~mm}$.

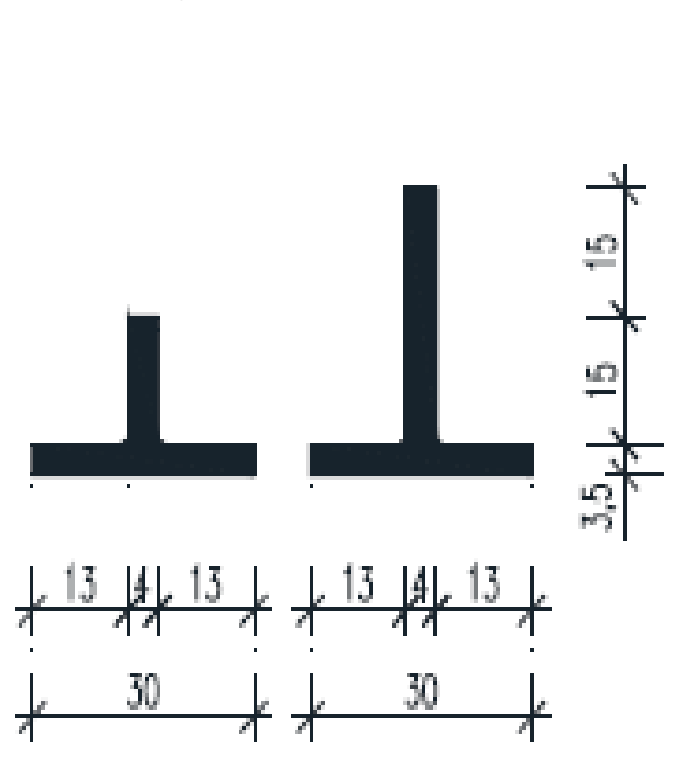

Figure 7. Shape of T-profile frame of (CFRP) (mm)
One or two T-shaped profiles were used to reinforce the RC beams. Of either 15 or $30 \mathrm{~mm}$ depth as shown in Table (1). They found that all strengthened beams with CFRP T-shaped profiles improved their ultimate capacity by 86 to $250 \%$ when compared to reference beam, depending on the number (one or two) and depth (15 or $30 \mathrm{~mm}$ ) of CFRP T-shaped profiles used. T30 profiles increased the bond area to cross sectional area offered greater resistance to concrete cover tensile splitting, as a result of the improved containment given by the concrete surrounding $\mathrm{T}$-shaped profile. Also concrete strength has been shown to influence capacity enhancement and CFRP performance, with beams with compressive strength (C50/60) showing greater strengthening potential as well as greater CFRP profile quality. The ultimate load and beam deformability were not affected by cutting the bottom transverse arm of steel stirrups during the NSM profile installation.

Table 1. Characteristic of RC beams

\begin{tabular}{cccc}
\hline Types & $\begin{array}{c}\text { Steel } \\
\text { Reinforcement in } \\
\text { Tension Zone }\end{array}$ & $\mathbf{f}_{\mathbf{c}}{ }^{\prime}$ & $\begin{array}{c}\text { CFRP } \\
\text { Profile }\end{array}$ \\
\hline C30/70 & $2 * 14$ & 30 & - \\
& & $2 * \mathrm{~T} 15$ \\
& & $1 * \mathrm{~T} 15$ \\
$\mathrm{C} 50 / 60$ & $2 * 14$ & & - \\
& & 60 & $2 * \mathrm{~T} 30$ \\
& & & $1 * \mathrm{~T} 150$ \\
& & & $2 * \mathrm{~T} 30$ \\
\hline
\end{tabular}

The flexural behavior of RC beams strengthened with (EBR-CFRP) sheet studied by El Gamala et al. (2019) [18]. Using various techniques, four beams were strengthened on the tension side with CFRP sheets (200 mm width). Two beams were 
strengthened with one or two sheets of CFRP. The third beam was strengthened with two sheets of CFRP folded and placed in two grooves (10 $\mathrm{mm}$ width and $20 \mathrm{~mm}$ depth). The fourth beam was strengthened by a hybrid technique using one sheet of CFRP placed in a one groove as NSM and one CFRP sheet as EBR. They found that the ultimate capacity of the strengthened beams is enhances when the amount of CFRP increased. The increasing of strength capacity by about $32.6 \%$ when using one CFRP sheet, while using two CFRP sheets lead to increase the strength capacity by about $56.1 \%$ compared to the reference beam. The hybrid beam had a 58.3 $\%$ higher ultimate ability and had improved ductile behavior than EBR. The beam who strengthened with CFRP sheets inserted in two grooves gave the lowest ultimate capacity among all strengthened beams, which may be due to the procedure used to fold and insert the dry fibers into the grooves. The bonding failed of the CFRP sheet was the main mode of failure in strengthened beams. The behavior of RC beams reinforced by GFRP bars and strengthened by CFRP sheets studied by Hassan et al. (2020) [19].The main parameters were GFRP reinforcement ratio and number of CFRP sheets. They found that when using a twin -layers of CFRP sheets to strengthening the beams reinforced by GFRP bars is very efficient. Beam that reinforced with $\left(f_{\mathrm{fmin}}\right)$, the strength capacity improvement about $90 \%$ compared with reference beam. The use of two layers of CFRP sheets has a higher impact on increasing the failure load for beams reinforced with minimum and balanced reinforcement ratios; failure load risen by (95 and 30.4) \% when the number of CFRP layers risen from (0 to 2 ) for beams with $\left(f_{\text {fmin }}\right.$ and $\left.f_{\mathrm{fb}}\right)$, respectively. Although increasing the number of CFRP sheets from one to two has negligible impact on the failure load for the beam reinforced $\left(1.3 f_{\mathrm{fb}}\right)$ and $\left(1.6 f_{\mathrm{fb}}\right)$, the failure load risen by (13 and $8.3 \%$ ), respectively. The max. ( $\mathcal{E}$ cu) was ranging between $(0.42 \%)$ to $(0.55 \%)$ respectively, these findings are higher than the standard values described by the ACIs which considers that the specified concrete grades $\left(\varepsilon_{\mathrm{cu}}\right)$ is between $(0.3 \%)$ and $(0.35 \%)$. The CEB-FIP model determined the size of crack for the GFRP reinforced members since the tested beams reinforced by GFRP had the same reinforcement ratios as the steel-reinforced members in this analysis, and the CEB-FIP equation also indirectly takes into account the effect of the CFRP reinforcement, while the ACI-440 equation shows little deal with the study's findings.

\subsection{Near Surface Mounted (NSM) For Flexural Strengthening}

In NSM system of strengthening, a groove is cut into the concrete cover of the tension side (for flexural strengthening) of the beam. The groove is then filled with a suitable adhesive, and the pre-stressed or non-pre-stressed FRP material (bar or strip) is installed and bonded into it Figure(8).When compared to EBR- FRPs, the NSM technique has an advantage in that the FRP material is protected against fire, collision, or other environmental hazards. There are two types of FRP bars that are widely used for NSM technique are [2]:

1- Round bar are typically manufactured by pultrusion methods and delivered to the job site as single bars or in rolls, based on the diameter of bar.

2- Rectangular bar and plates are typically produced by pultrusion methods and delivered to the job site in a roll. 


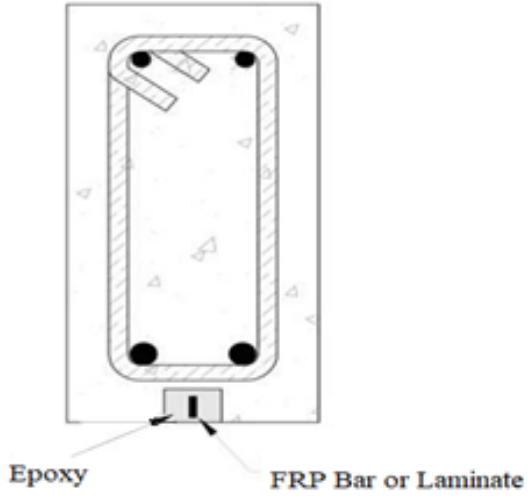

Figure 8. Near surface mounted for flexural strengthening

The behavior RC beams strengthened with NSMCFRP strips studied by Teng et al. (2006) [20]. The main parameter of this study was the embedment length $(500 \mathrm{~mm}, 1200 \mathrm{~mm}, 1800 \mathrm{~mm}$ and $2900 \mathrm{~mm}$ ) of the NSM-CFRP strip and have a width of (16) $\mathrm{mm}$ and a thickness of $(2 \mathrm{~mm})$. They found that bonding failed failure was the primary failure mode in all tested beams, with the exception of the beam with the longest embedment length. The beam with a bonded length of $500 \mathrm{~mm}$ had no increase in strength compared with the reference beam. This is possible because the bonded length ended within the constant moment zone, implying that the failure occurred in the unstrengthen zone. As compared to the reference beam, the CFRP strips with lengths of 1200, 1800, and $2900 \mathrm{~mm}$ improved ultimate capacity by 30,90 , and $106 \%$, respectively. Concrete cover separation was the failure mode of beams strengthened with CFRP strip of length $(1200,1800 \mathrm{~mm})$ Figure (9). The beam with a $2900 \mathrm{~mm}$ FRP bond length was failed due to concrete crushing followed by bonding failed in the peak moment region. They found that the bonding failed failures in beams were primarily caused by concrete cracking in the cover area due to both shear and flexural effect.

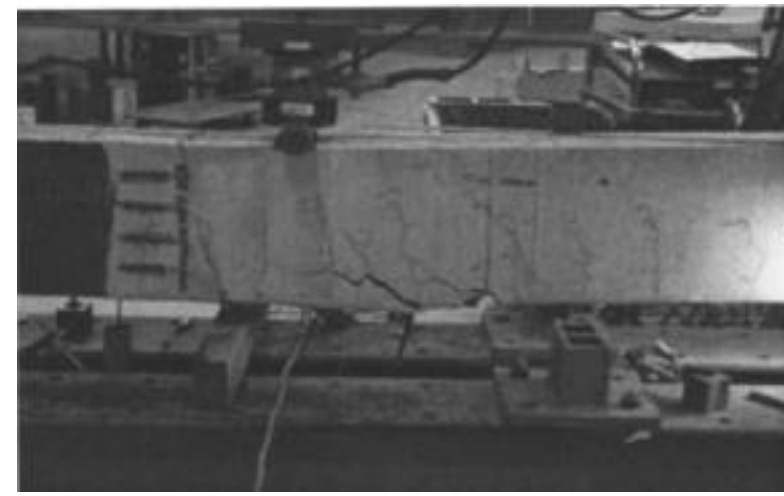

Figure 9. Mode failure of beam with 1200, $1800 \mathrm{~mm}$ NSM FRP

The flexural behavior of RC beams strengthened with NSM technique using CFRP bar studied by Soliman et al. (2008) [21]. The main parameters was steel reinforcement ratio and various bonded length of CFRP bars (9.5 mm- diameter) as shown in Table (2). The cross section of test specimens as shown in Figure (10).

Table 2. Description of test beams

\begin{tabular}{|c|c|c|c|}
\hline Beam ID & $\begin{array}{c}\text { Diameter of } \\
\operatorname{CFRP}(\mathbf{m m})(\mathbf{d})\end{array}$ & $\begin{array}{l}\text { Steel } \\
\text { ratio }\end{array}$ & $\begin{array}{l}\text { Bonded } \\
\text { length }\end{array}$ \\
\hline & \multicolumn{3}{|c|}{ Group A } \\
\hline A0 & \multirow{3}{*}{\multicolumn{2}{|c|}{$\begin{array}{c}\text { Control } \\
\text { beam } \\
0.8 \%\end{array}$}} & \\
\hline A1 & & & $24 \mathrm{~d}$ \\
\hline $\mathrm{A} 2$ & & & $48 \mathrm{~d}$ \\
\hline & \multicolumn{3}{|c|}{ Group B } \\
\hline B0 & \multirow{5}{*}{9.5} & $\begin{array}{c}\text { Control } \\
\text { beam }\end{array}$ & \\
\hline B1 & & & $12 \mathrm{~d}$ \\
\hline B2 & & $0.4 \%$ & $24 \mathrm{~d}$ \\
\hline B3 & & & $48 \mathrm{~d}$ \\
\hline B4 & & & $60 \mathrm{~d}$ \\
\hline
\end{tabular}
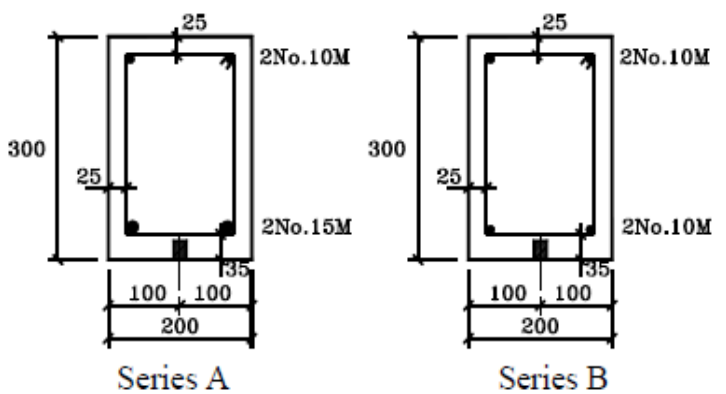

Figure 10. Cross section of test specimens 
They found that bonding failed of the FRP from the concrete surface controls the usual mode of failure for RC beams reinforced with NSM-FRP bars, as all of the tested strengthened beams in this study failed due to bonding failed of CFRP bar near the position of shear crack in the form of concrete cover separation at the level of the steel tensile reinforcement bars. For Series A, when using bonded length $24 \mathrm{~d}$, the ultimate capacity was not increased, but using $48 \mathrm{~d}$ bonded length increased the capacity by around $18.7 \%$ when compared to the control beam. For group B , when using the shortest bonded length of $12 \mathrm{~d}$, the ultimate capacity increased by $22 \%$, while the beams strengthened with bonded lengths of 24d, 48d, and 60d increased their ultimate capacity by 32,71 , and $75 \%$, respectively, when compared to the control beam. The behavior of RC beams strengthened in flexure with NSM technique using GFRP and CFRP studied by ElGamal, et al. (2016) [22]. The main parameters was technique used (NSM or Hybrid), amount of FRP material, FRP type (carbon or glass) and tension steel reinforcement ratio. First group have seven beams with two steel bar in tension side with diameter of $12-\mathrm{mm}$, while the tension side of the second group (three beams) had four steel bar with diameter of 12-mm steel bars. For the first group, two beams was strengthened with one or two $10 \mathrm{~mm}$ diameter CFRP bars, two beams were strengthened with one or two 10 mm- diameter GFRP bar, two beams was strengthened with NSM and EBR (hybrid technique); one beam was strengthened with CFRP sheet and CFRP bar, the second was strengthened with CFRP sheet and GFRP bar and one beam was held unstrengthen as a control beam. For the second group, two beams were strengthened with one or two CFRP bars and one beam held unstrengthen as a control beam. They found that when compared to the reference beam, all strengthened beams showed an increase in ultimate ability ranging from 31 to $133 \%$. However, when compared to the NSM technique, the hybrid technique showed limited benefit. The (NSM-CFRP) reinforced beam had greater maximum load capacity but little ductile behavior than the (NSM-GFRP) beams.

While the (NSM-GFRP) reinforced beam exhibited excellent ductility with high deflection values at maximum load. Debonding was the main issue with NSM with CFRP bars. The behavior of RC beams strengthened in flexure with NSM technique using steel and CFRP bars studied by Hosen, et al.(2016)[23]. One beam was held unstrengthen as a reference beam, four beams was strengthened with steel bars with different numbers and different diameters and one beam was strengthened with CFRP bar as shown in Table (3). NSM steel and carbon bars have a bonded length of $1900 \mathrm{~mm}$. Steel and CFRP bar inserted into grooves as shown in Figure (11).

The main parameters in this study was the number, diameter and type of strengthening materials. They found that using NSM steel bar strengthening to improve the flexural properties of RC beams is very expensive. As compared to the control beam, the strengthened beams had finer cracks with closer spacing and a higher first crack load. The first crack load is improved from (27 to $69 \%$ ), and the maximum load capacity is improved from (43 to $84 \%$ ), by increasing the amount of NSM steel bar from ( $2 \phi 8)$ to $(2 \phi 12)$, respectively. The (NSM-CFRP) improve the first crack load and maximum load capacity of (59and $92 \%$ ), respectively, as compared with the reference beam. 
Table 3. Description of test beams

\begin{tabular}{|c|c|c|c|}
\hline & Strengthening & bars & \multirow[b]{2}{*}{$\begin{array}{c}\text { Strength } \\
\text { ening }\end{array}$} \\
\hline $\begin{array}{c}\text { Beam } \\
\text { ID }\end{array}$ & Number & Diameter & \\
\hline R.B & $\begin{array}{c}\text { Reference } \\
\text { beam }\end{array}$ & $\begin{array}{c}\text { Unstrength } \\
\text { en }\end{array}$ & \\
\hline N.1 & 2 & 8 & \\
\hline N.2 & 2 & 10 & \multirow{3}{*}{ Steel } \\
\hline N.3 & 1 & 16 & \\
\hline N.4 & 2 & 12 & \\
\hline N.5 & 2 & 12 & $\begin{array}{c}\text { CFRP } \\
\text { bars }\end{array}$ \\
\hline
\end{tabular}

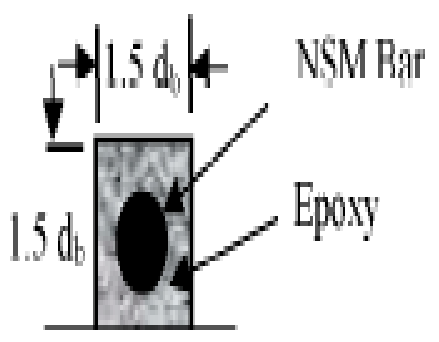

Fionre11. Cross section of ornove

The flexural behavior of $\mathrm{RC}$ beams using different techniques under static loading and tested under four point loading studied by Elshafiey, et al.(2017)[24]. One beam was held unstrengthen as a reference beam, three beams were strengthened, the first beam was strengthened with two NSM CFRP strips with cross section $1.2 \times 10 \mathrm{~mm}(\mathrm{BF})$, the second with EB steel plate with cross section $1.3 \times 135 \mathrm{~mm}$ with end anchored with six bolted at each end of diameter $10 \mathrm{~mm}$ (BS) and the third beam strengthened with layer of ultra-high performance strain hardening cementitious composite (UHP-SHCC) with cross section $(60 \times 150 \mathrm{~mm})(\mathrm{BU})$ techniques as shown in table (4).
Table 4. Description of tested beams

\begin{tabular}{|c|c|c|c|c|}
\hline $\begin{array}{c}\text { Beam } \\
\text { ID }\end{array}$ & $\begin{array}{c}\text { Dimension } \\
\mathrm{s}\end{array}$ & $\begin{array}{l}\text { Strengthenin } \\
\text { g technique }\end{array}$ & Material & $\begin{array}{c}\text { Dimension } \\
\text { material }\end{array}$ \\
\hline $\mathrm{BC}$ & $\begin{array}{c}150 \times 300 \times \\
3000\end{array}$ & - & - & - \\
\hline BS & $\begin{array}{c}150 \times 300 \times \\
3000\end{array}$ & $\begin{array}{c}\text { EB plate } \\
\text { with } \\
\text { end anchors }\end{array}$ & Steel & $\begin{array}{l}1.3 \times 135 \\
\text { mm plate }\end{array}$ \\
\hline $\mathrm{BU}$ & $\begin{array}{c}150 \times 300 \times \\
3000\end{array}$ & $\begin{array}{l}\text { Adding a } \\
\text { layer of } \\
\text { mortar }\end{array}$ & $\begin{array}{l}\text { UHP- } \\
\text { SHCC }\end{array}$ & $\begin{array}{c}150 \times 60 \\
\mathrm{~mm} \\
\text { layer }\end{array}$ \\
\hline $\mathrm{BF}$ & $\begin{array}{c}150 \times 300 \times \\
3000\end{array}$ & NSM strips & CFRP & $\begin{array}{l}1.2 \times 10 \\
\text { mm } \\
\text { strips }\end{array}$ \\
\hline
\end{tabular}

All beams had two steel bars with a diameter of $12 \mathrm{~mm}$ in the bottom and two steel bars with a diameter of $8 \mathrm{~mm}$ in the top. To prevent shear failure, stirrups diameter is $10 \mathrm{~mm}$ were spaced $100 \mathrm{~mm}$ for length equal to $1000 \mathrm{~mm}$ from right and left support, however the mid length $700 \mathrm{~mm}$, the stirrups were spaced at $230 \mathrm{~mm}$. They found that Strengthening of the RC beams improved the static flexural performance in terms of the flexural stiffness, ultimate load and the yield load compared with the reference beam .With a yield load improvement of $67 \%$ over the reference beam, beam (BS) obtained the maximum yield load improvement. Beams (BU) and (BF) produced comparable improvement in the yield loads of $62 \%$ and $61 \%$ respectively. The ultimate load increased by about $83 \%, 72 \%$, and $63 \%$ for beams (BF), (BS), and (BU), respectively, over the reference beam. The yielding of the steel plate, followed by the peeling off of the concrete cover, the rupture of the UHP-SHCC, and the rupture of CFRP strips, was the mode of failure of the reinforced $\mathrm{RC}$ beams $\mathrm{BS}, \mathrm{BU}$, and $\mathrm{BF}$, respectively. Thus the ultimate capacity of the strengthening materials were reached. The (NSM-CFRP) technique is the most convenient technique since this technique increases ductility 
comparted with the other strengthening techniques under static loading.

\section{Conclusions}

1. FRP materials are commonly used in civil engineering construction purposes owing their advantages like lightweight, corrosion resistance, high strength, and various types available, ease of installation, lower installation costs, shorter construction time and lower maintenance cost .

2. The common techniques of strengthening the beam with FRP materials are with Near Surface Mounted (NSM) or Externally Bonded Reinforcement (EBR).

3. The use of FRP materials to strengthening RC beam lead to improve crack pattern, ultimate load and deflection significantly.

4. The strengthened beams had finer cracks with closer spacing and a higher first crack load.

5. The hybrid technique showed limited benefit when compared to the NSM and EBR techniques.

6. The (NSM-CFRP) reinforced beam had greater ultimate capacity but little ductile behavior than the (NSM-GFRP) beams. The (NSM-GFRP) reinforced beam exhibited excellent ductility with high deflection values at maximum load.

7. The use of NSM steel bar strengthening lead to improve the flexural properties of $\mathrm{RC}$ beams but is very expensive.

8. Bonding failed of the FRP, concrete crushing, fracture of the FRP, and shear or flexural failure with steel yielding are the most common modes of failure of RC beam strengthened by FRP materials.

\section{Conflict of Interest}

The authors confirm that the publication of this article causes no conflict of interest.

\section{Abbreviations}

$\begin{array}{ll}\text { NSM } & \text { Near surface mounted } \\ \text { EBR } & \text { Externally bonded reinforcement } \\ \text { FRP } & \text { Fiber reinforcement polymer } \\ \text { CFRP } & \text { Carbon fiber reinforcement } \\ \text { GFRP } & \text { Glass fiber reinforcement polymer } \\ \text { RC } & \text { Reinforced concrete } \\ \phi & \text { Diameter bar }\end{array}$

\section{References}

1. Al-Saadi, Nihad Tareq Khshain, et al. (2019). "A state-of-the-art review: Nearsurface mounted FRP composites for reinforced concrete structures". Construction and Building Materials, volume 209, pp: 748-769. https://doi.org/10.1016/j.conbuildmat.2019 .03 .121 .

2. ACI 440.2R-17. (2017). "Guide for the design and construction of externally bonded FRP systems for strengthening concrete structures". ACI Committee 440, American Concrete Institute, Michigan.

3. Module, I. E. (2004). "An introduction to FRP strengthening of concrete structures". Prepared by ISIS Canada, a Canadian Network of Centres of Excellence.

4. Tsai, Stephen W., and H. Thomas Hahn. (1980). "Introduction to composite materials". CRC Press, Lancaster, Volume 1.

5. Newhook, J., and D. Svecova. (2007). "Reinforcing concrete structures with fiber reinforced polymers". Design manual ISIS Can, Volume 151, No. 3, pp: 449-458.

6. Wu, Z., and Fahmy, M. F. (2020). "Structures strengthened with bonded composites". 1st ed.,Woodhead Publishing.

7. ACI 440.2R-15. (2015). "Guide for the design and construction of externally bonded FRP systems for strengthening 
concrete structures". ACI Committee 440, American Concrete Institute, Michigan.

8. Khalid Heiza, A. N., Meleka, N., and Tayel, M. (2014). "State- of- the art review: strengthening of reinforced concrete structures-different strengthening techniques". In Sixth International Conference on Nano-Technology in Construction, Volume 6, pp: 22-24. https://www.researchgate.net/ publication/260991475_State-of.

9. Paul, J. H., and SE, P. (2002). "Repair, renovation and strengthening of concrete structures", ACI Int. Conf, Mexico.

10. Mutalib, A. A., and Hao, H. (2011). "Numerical analysis of FRP-compositestrengthened $R C$ panels with anchorages against blast loads". Journal of Performance of Constructed Facilities, Volume 25, Issue 5, pp: 360-372. https://doi.org/10.1061/(ASCE)CF.19435509.0000199.

11. Sabau, C., Popescu, C., Sas, G., Schmidt, J. W., Blanksvärd, T., and Täljsten, B. (2018). "Strengthening of RC beams using bottom and side NSM reinforcement", Composites Part B: Engineering, Volume 149, pp: 8291.

https://doi.org/10.1016/j.compositesb.2018 .05 .011 .

12. De Lorenzis, L., and Teng, J. G. (2007). "Near-surface mounted FRP reinforcement: An emerging technique for strengthening structures". Composites Part B: Engineering, Volume 38, Issue 2, pp: 119-143.

https://doi. org/10.1016/j.compositesb.2006.08.003.

13. Mohammed, D. H. (2007). "Behavior of reinforced concrete beams strengthened by cfrp in flexure". Doctoral dissertation. Ph. D. Thesis, University of Technology, Iraq.

14. Husain, H. M., Al-Oukaili, N. K., and ALI, D. D. (2009). "Experimental investigation of reinforced concrete flexural beams strengthened or repaired with CFRP". Journal of Engineering, Volume 15, Issue 3, $\quad$ pp: $\quad 3891 \quad-3906$. https://www.iasj.net/iasj/article/24225.
15. Attari, N., Amziane, S., and Chemrouk, M. (2012). "Flexural strengthening of concrete beams using CFRP, GFRP and hybrid FRP sheets". Construction and Building Materials, Volume 37, pp: 746-757. https://doi.org/10.1016/j.conbuildm at.2012.07.052.

16. Hameed, Bayda M., Husain Khalaf Jarallah, and Mithaq A. Louis., (2013). "Load-deflection behavior of reinforced concrete beams strengthened with CFRP sheets." Journal of Engineering and Sustainable Development Volume 17, Issue 4, pp: 14-26. https://www.iasj.net/ iasj/article/81355.

17. Kotynia, R., and Cholostiakow, S. (2015). "New proposal for flexural strengthening of reinforced concrete beams using CFRP Tshaped profiles". Polymers, Volume 7, Issue $\quad 11, \quad$ pp: 2461-2477. https://doi.org/10.3390/polym 7111524.

18. El Gamal, S., Al-Nuaimi, A., Al-Saidy, A., and Al-Shanfari, K. (2019). "Flexural behavior of $R C$ beams strengthened with CFRP sheets using different strengthening techniques". The Journal of Engineering Research [TJER], Volume 16, No.1, pp: 35-43. https://doi .org/10.24200/tjer.vol16iss1pp35-43.

19. Hassan, H. F., Medhlom, M. T. K., Ahmed, A. S., and Al-Dahlaki, M. H. (2020). "Flexural performance of concrete beams reinforced by GFRP bars and strengthened by CFRP sheets". Case Studies in Construction Materials, Volume 13, Article 00417. org/10.1016/j.cscm.2020.e00417.

20. Teng, J. G., De Lorenzis, L., Wang, B., Li, R., Wong, T. N., and Lam, L. (2006). "Debonding failures of RC beams strengthened with near surface mounted CFRP strips". Journal of composites for construction, Volume 10, Issue 2, pp: 92105. https://doi.org/10.1061/(ASCE)109 00268(2006)10:2(92).

21. Soliman, S. M., El-Salakawy, E., Benmokrane, B., and Abdel Baky, H. 
(2008). "Experimental and numerical investigation of $R C$ beams strengthened in bending with near surface mounted CFRP". In 5th International conference on Advanced Composite Materials in Bridges and Structures (ACMBSV).

22. El-Gamal, S. E., Al-Nuaimi, A., Al-Saidy, A., and Al-Lawati, A., (2016). "Efficiency of near surface mounted technique using fiber reinforced polymers for the flexural strengthening of RC beams". Construction and Building Materials, Volume 118, pp: 52-62. https: //doi.org/10.1016/j.conbuildmat.2016.0415 2 .
23. Hosen, M., Jumaat, M. Z., Alengaram, U. J., Islam, A. B. M., and Bin Hashim, H. (2016). "Near surface mounted composites for flexural strengthening of reinforced concrete beams". Polymers, Volume 8, Issue 3, pp: 67. https://doi. org/10.3390/polym8030067.

24. El- Shafiey, T. F., Etman, E., Hussein, M., and El-Bosiely, M. M., (2017)."Behavior of strengthened $R C$ beams using different techniques under static loading", International Conference on Advances in Structural and Geotechnical Engineering (ICASGE'17). 